\title{
Effects of Integrated Marketing Communication Channels on Brand Equity at Samsung Phone Kenya
}

\author{
Jesca Nkatha Kubania ${ }^{1}$, Dr. Assumptah Kagiri ${ }^{2}$ \\ ${ }^{1}$ MBA, JOMO KENYATTA UNIVERSITY OF AGRICULTURE AND TECHNOLOGY \\ ${ }^{2}$ SUPERVISOR, JOMO KENYATTA UNIVERSITY OF AGRICULTURE AND TECHNOLOGY
}

\begin{abstract}
The purpose of this thesis was to examine the effects of integrated marketing communication channels on brand equity at Samsung phone Kenya Ltd, and more specifically on awareness and loyalty that are said to be critically affected by communication. In order to capture the required information the study was guided by four objectives; To determine the influence of electronic media on brand equity at Samsung phone Kenya, to establish the extent to which print media influence brand equity at Samsung phone Kenya, to assess the effects of social media on brand equity at Samsung phone Kenya and to examine the influence of online media on brand equity at Samsung phone Kenya. The paper reviewed past research and theories regarding ways of measuring the communication effects of the major IMC tools which include Television, print, online and social media. To establish validity, the research instrument was given to two experts who were experienced in integrated marketing communication channels and brand equity. Validity was determined by use of content validity index (CVI) Whereby a CVI of 0.747 was obtained. For reliability analysis the study involved questionnaires from 38 respondents and Cronbach's alpha was calculated by application of SPSS. The Study employed a descriptive survey design utilizing both primary and secondary data. Three hundred and eighty four copies of Structured and unstructured questionnaires were used to collect primary data and were administered to the Samsung mobile phone users visiting the Nairobi service centers while secondary data was collected through literature and document review. The postulated objectives were tested by employing the Pearson Correlation statistical tool which was facilitated by the statistical package for social sciences (SPSS), while the main method of data presentation was frequency distribution tables. Findings of the study showed that the variables considered that is; electronic media, social media, print media and online media significantly influence brand equity at Samsung mobile Kenya with online media having the biggest influence followed by social media, electronic media and lastly print media. The study therefore recommends that Samsung mobile Kenya should increase more funding on advertising in online media, social media, electronic media and print media in the order of the most influential to further boost brand equity. Further research was recommended on the different forms of integrated marketing communication channels on brand equity among Samsung competitors like LG, Techno, Sony and others so as to compare the market trends. It would be interesting to see the advantages and drawbacks of different integrated marketing communication channels, as well as which channel has been most effective in brand equity.
\end{abstract}

Keywords: Electronic media, Print media, Online media, Social media

\section{Introduction}

Integrated Marketing Communications (IMC) has emerged as the dominant approach used by companies to plan and execute their marketing communication programs. Many marketers, as well as advertising agencies are embracing the IMC paradigm and developing integrated campaigns that use a variety ways to communicate with their target audiences, (McArthur and Griffin 2009, Belch \& Belch, 2011, Duncan 2011).Although it makes for exciting times the adoption of new technologies, and the advertising in them, has expanded at a faster rate than the knowledge of how to leverage them, (Romaniuk, Beal, \& Jeans, 2012)

As marketers work to find the right way to send the right message to the right person at the right time they are looking beyond advertising and the traditional mass media-focused approach to marketing communication, (Lal, Quelch \& Rangan 2011).The demand for mobile phones in East Africa in the last few years has been more than most people expected and continues to expand. Operators have traditionally targeted urban areas, but it is the demand from rural and low income areas that have exceeded all expectations. In African countries alone Kenya included, and according to the Communications Commission of Kenya (CCK), mobile phone usage has grown an average of 65 percent a year for the past five years. This is twice the rate of growth in Asian countries. Penetration of mobile telephony in Kenya, like many other developing countries, is mainly driven by affordability and innovation. As a result of this every mobile phone company has been trying all strategies so as to have a competitive edge hence win a considerable market share as a result of competition. New mobile phone providers have been mushrooming every single day with the same aim of sharing in the industry's returns.

According to insider business, an international business newspaper, Samsung is losing its grip as one of the top Smartphone markets in the world. For example in china, the biggest Smartphone market in the world —in the 12 months ending May 2015, Samsung's Smartphone sales halved in the country. In 12 months, it dropped from the top Smartphone seller in the country to the fourth. Apple was a key beneficiary of this collapse, as was Huawei and Xiaomi. (Gartner Data Report)On the same report, Samsung's global Smartphone sales slumped in Q2 2015 to close at a market share of 21.9\% down from 26.2\% in Q2 2014, even as the global market grew $13.5 \%$ year-on-year. Samsung is still number 1, despite its share dropping by nearly five percentage points.(Gartner Data Report).The result of all this? Samsung's profits dropped 8\% year-on-year in Q2 2015 — its fifth consecutive decline. According to Bloomberg, it has lost \$44 billion in value since April.

Based on the Kenya economic report (2014) Samsung is losing its market share percentage from $38 \%$ in 2012 to $26 \%$ in 2014 which is highly attributed to the increased market 


\section{International Journal of Science and Research (IJSR) \\ ISSN (Online): 2319-7064 \\ Index Copernicus Value (2013): 6.14 | Impact Factor (2015): 6.391}

players and the aggressive marketing campaigns adopted by its competitors amongst other factors.

\subsubsection{Specific Objectives}

1) To determine the influence of electronic media on brand equity at Samsung phone Kenya

2) To establish the extent to which print media influence brand equity at Samsung phone Kenya

3) To assess the effects of social media on brand equity at Samsung phone Kenya

4) To examine the influence of online media on brand equity at Samsung phone Kenya

\section{Literature Review}

\subsection{Theoretical Framework}

\subsubsection{Consumer Decision Model (Howard et al. 1998)}

In Consumer Decision Model, (Howard et al. 1998), the purchasing behavior is determined by the variety of advertisement exposure. Impact of the advertisement exposure is not directly intended to purchasing behavior but it will pass through several stages. First, the advertisement will directly develop brand awareness. In the context of TVbased advertisement repeated advertisement program could potentially develop positive perception.

Research conducted by Lukia Zuraida and Uswatun(2001), who used this model to explain the advertisement effectiveness of detergent-related branded products namely Rinso, Attack and Soklin had several findings which included; Advertisement significantly influence brand awareness, advertisement significantly influence confidence, advertisement significantly influence attitude, Brand awareness significantly influence confidence, Brand awareness significantly influence attitude, and lastly brand awareness strengthens the relationship between advertisement message and confidence.

\subsubsection{Social Exchange Theory}

The theory attempts to explain the nature of the relationships between service quality, perceived value, satisfaction and loyalty. The theoretical model adopted for this study was derived from the social exchange theory, (Homans, 1958), which posits that all human relationships are formed by the use of cost-benefit analysis and comparisons of alternatives. Although service loyalty is sometimes viewed as a result of cognitive rather than emotional consumer outcomes, (Pritchard et al, 2013) .The theory can be applied to a range of contexts including, for example, compliments from acquaintances, support among co-workers, information flows from firms, trading among nations and relationships between firms and customers.

The purpose of the affect theory of social exchange is to incorporate emotions as a core feature of social exchange processes, where a social exchange is conceptualized as a joint activity, with at least two parties, and each party has something the other values, (Lawler, 2011).

\subsection{Conceptual Framework}

The Conceptual framework of this study includes independent variables; electronic media, print media, social media and online media. Independent variables are the factors that the researcher thinks that will explain the variables while the dependent variables are those that the researcher attempts to predict, (Orodho and Kombo, 2002).The conceptual framework identifies the independent variable that affect the dependent variable which is brand equity at Samsung phone Kenya.

\section{Research Gaps}

The available literature has concentrated on various other contexts in developed countries. The literature further explains the situation of various organizations at different times when the extent of technology and globalization was not as advanced as in the current situation. Further the literature does not give a comprehensive review of effects of all integrated marketing communication channels hence the current study aims to conduct an in-depth investigation on the effects of communication marketing channels on brand equity with reference to Samsung mobile Kenya

\subsection{Data Analysis}

Multiple regression was used in the analysis of quantitative data in order to establish the significance of each of the integrated marketing communication channel on brand equity. The basic formula of multiple regression, (Hair et al., 2010), is as below

\section{Regression model \\ $Y=\beta_{0}+\beta_{1} X_{1}+\beta_{2} X_{2}+\beta_{3} X_{3}+\beta_{4} X_{4}+\varepsilon$}

Where; $Y=$ brand equity, $\beta 0=$ Constant Term, $\beta 1-\beta 4$ (Coefficients), $\mathrm{X}_{1}$-electronic, $\mathrm{X}_{2}$-print, $\mathrm{X}_{3}$-social, $\mathrm{X}_{4}-$ online, $\varepsilon=$ Error term

Coding was done in SPSS, analyzed and the output interpreted in frequencies, percentages, mean scores and standard deviation. Qualitative data from semi-structured and open ended questions was analyzed through a deductive approach, according to key themes and concepts using simple coding to identify and group the responses. The researcher needed to keep the variation in respondents' answers but at the same time sort them into meaningful categories that would aid comparison between respondents and the identification of commonalities, (Kumar, 2012).

\subsection{Data presentation}

Quantitative data findings were presented using tables and pie charts. This was enhanced by an explanation and interpretation of the data. Inferential statistics such as, regression analysis was used to establish the relationship that exists between the different marketing communication channels and brand equity. Quantitative reports were generated through tabulations, percentages, and measures of central tendency. Cooper and Schindler (2011), note that the use of percentages is important for two reasons; first they simplify data by reducing all the numbers to range between 0 and 100 . Second, they translate the data into standard form with a base of 100 for relative comparisons. 


\section{International Journal of Science and Research (IJSR) \\ ISSN (Online): 2319-7064 \\ Index Copernicus Value (2013): 6.14 | Impact Factor (2015): 6.391}

Qualitative data has been presented through narrative format. The narrative is supported using findings from raw data and presented as direct quotes to support and illustrate the themes. The findings have also been presented in the context of the previous research and theories. A discussion of the existing literature and how this study contributes to the area has been included.

\section{Results and Discussion}

\section{Response Rate}

The targeted sample size was 384 participants. Those filled and returned questionnaires were 366 respondents making a response rate of $95.31 \%$. According to Mugenda \& Mugenda (2008), a response rate of $50 \%$ is adequate for analysis and reporting; a rate of $60 \%$ is good and a response rate of $70 \%$ and over is excellent. This means that the response rate for this study was excellent and therefore enough for data analysis and interpretation.

\section{Electronic Media and brand equity}

The study sought to determine the influence of electronic media on brand equity at Samsung phone Kenya. This included the influence of television and radio as marketing communication channels. The results indicate that respondents agreed with the statement that they first gained knowledge of Samsung phone through television media (Mean=3.8466, SD=.91449) and that watching the television stimulates them to buy the Samsung phone repeatedly (Mean=3.8466, SD=.84751). Further as far as radio communication channel is concerned, respondents agreed to low extent with the statements that they first gained knowledge of Samsung phone through television media and that watching the television stimulates them to buy the Samsung phone repeatedly (Mean=2.7519, SD=.84751) and (Mean=2.6439, SD=.83009) respectively. This implies that TV as a communication channel influences brand equity of Samsung phones more than radio as a communication channel. This may be due to the fact that customers are able to see, like and choose the phones being advertised using TV as compared to radio. The findings of this study concurs with previous studies such as Taylor et al., (2013) in his research on the effects of Television found that a single TV exposure still has a strong affect on short term sales and that higher frequency typically brings extra sales but the added effect diminishes.

\section{Print Media and brand equity}

The study further found it necessary to determine the influence of print media on brand equity of Samsung mobile phones. These included the influence of newspapers and magazines on brand equity which is operationalized on the basis of gained knowledge on the first purchase and the stimulation to buy.

The results indicate that respondents agreed that print media is important in creating brand equity of Samsung phones in Kenya. This is manifested in the respondents views on the constructs considered. For instance, they agreed most on the statements that they first gained knowledge of Samsung phone through reading the magazine and that reading a magazine stimulates them to buy the Samsung phone repeatedly (Mean=4.0458, $\mathrm{SD}=.77323)$ and (Mean=4.0231, $\mathrm{SD}=.78222$ ) respectively as far as magazines is concerned and (Mean=3.8923' $\mathrm{SD}=.73922)$ and (Mean=4.0150, $\mathrm{SD}=.74858$ ) as far as newspaper is concerned respectively. Further magazines showed higher mean agreement as compared to newspapers which may be as a result of many varieties of phones being advertized on magazine pages as compared to newspaper pages.

\section{Social Media and brand equity}

The study determined the influence of social media on brand equity of Samsung phone in Kenya. Social media consists of Facebook and twitter. The findings show that facebook influences most the brand equity of Samsung phones as compared to twitter. This is as manifested with higher means on the statements that they first gained knowledge of Samsung phone through Facebook (Mean= 4.7669, $\mathrm{SD}=.86065$ ) and that through Facebook they are stimulated to buy the Samsung phone repeatedly (Mean=4.7669, $\mathrm{SD}=.86065$ ). This implies that Facebook is mostly used by customers as well as Samsung dealers as a marketing communication channel thereby creating brand equity as compared to twitter.

\section{Online media and brand equity}

The study also determined the influence of online media consisting of emails and websites on brand equity of Samsung phones in Kenya. This was informed by the fact that many customers can now access emails and websites due to rapid technological advancement across the country and in different age groups. The results indicate that website is the channel that was agreed upon by respondents as having influenced brand equity of Samsung phones the most as compared to emails. For instance respondents agreed most on the statement that the website stimulates them to buy the Samsung phone repeatedly (Mean=3.8864, $\mathrm{SD}=.90501$ ) as compared to emails (Mean=3.2212, $\mathrm{SD}=.93719)$. This implies that websites are most visited by customers who are willing to purchase some phones as compared to use of emails.

\section{Brand equity}

Brand equity being the dependent variable, the study determined how it is influenced by integrated marketing communication channels using certain statements on a Likert scale. This is operationalized through brand loyalty and awareness. The findings indicates that respondents were in more agreement with the statement that they have bought from this service provider for a number of years because they offer satisfactory services (Mean=3.9851, SD=.79458). Further they also indicated that the service provider stimulates them to buy repeatedly (Mean=3.9774, SD=. 72264). This implies that Samsung phones have built a brand to their customers through satisfactory services, quality phones and therefore customers are willing to purchase repeatedly. 


\section{International Journal of Science and Research (IJSR) \\ ISSN (Online): 2319-7064 \\ Index Copernicus Value (2013): 6.14 | Impact Factor (2015): 6.391}

\section{Conclusions}

Pearson correlation was used to measure the degree of association between variables under consideration i.e. independent variables and the dependent variables. The analysis showed that online media has the strongest positive influence on brand equity implying that the relationship is statistically significant. In addition, electronic media, print media, online media and social media are positively correlated to brand equity implying statistically significant relationships. The correlation matrix implies that the independent variables are very crucial determinants of brand equity as shown by their strong and positive relationship with the dependent variable; brand equity.

Through multiple regression analysis, the four independent variables that were studied explain a significant influence on the brand equity. This implies that these variables are significant therefore need to be considered in any effort to boost brand equity of Samsung phones in Kenya.

\section{Recommendations}

The study therefore recommends that Samsung mobile Kenya should put more emphasis on advertising in the four media channels analyzed beginning with online media taking the biggest chunk of the budget followed by social media then electronic media and lastly print media as all media plays a significant role in influencing brand The study further recommends that apart from integrated communication media, other forms of marketing should be put in place

\section{Areas for Further Study}

One of the areas that may be interesting to look into is the different forms of integrated marketing communication channels on brand equity among Samsung competitors like LG, Techno, Sony and others so as to compare the market trends. It would be interesting to see the advantages and drawbacks of different other integrated marketing communication channels, as well as which channel has been most effective in brand equity. More research should be conducted in the developing countries in order to compare the findings with those studies conducted in the developed countries.

\section{References}

[1] Aaker, A, D. (2009). Managing brand equity: capitalizing on the value of a brand name. Kindle Edition. New York:Free Press.

[2] Baker, T. L. (2011).Doing social research. New York: McGraw Hill

[3] Belch G. E. \& Michael A. B. (2004) .Advertising and promotion: an integrated marketing communication perspective. $5^{\text {th }}$ ed. New York, NY: McGraw Hill/Irwin

[4] Binet, L. \& Field, P. (2009).Empirical Generalizations about advertising campaign success, Journal of Advertising Research, 49(2), 130-133.

[5] Briggs, R., R. Krishnan, \& Norm, B. (2005). Integrated multichannel communication strategies: evaluating the return on marketing objectives-The case of the 2004 FORD F-150 launch. Journal of Interactive Marketing, 19(3), 81-90.

[6] Bruhn, M., Schoenmueller V. \& Schafer D.B. (2012).Are social media replacing traditional media in terms of brand equity creation? Management Research Review, 35(9), 770-790.

[7] Bruner, G. C. \&Anand, K.(2000).Web commercials and advertising hierarchy-of-effects, Journal of Advertising Research, 40 (1/2), 35-42.

[8] Buil, I., De Chernatony, L., \& Martínez, E. (2008). A cross-national validation of the consumer based brand equity scale. Journal of Product \& Brand Management, 17(6), 384-392.

[9] Calder, B. J. \&Malthouse, E. C. (2005). Managing media and advertising change with integrated marketing.Journal of Advertising Research, 45(4), 356361.

[10]Chang, C.\& Thorson, D. (2004).Television and web advertising synergies. Journal of Advertising, 33(2), 7484.

[11] Christodoulides, G., Jevons, C., \& Bonhomme, J. (2012). Memo to marketers: Quantitative evidence for change: How user-generated content really affects brands. Journal of Advertising Research, 52, 53-64.

[12] Danaher, P. J. \& Dagger, T. S. (2013).Comparing the relative effectiveness of advertising channels: a case study of a multimedia blitz campaign.Journal of Marketing Research, 517-534.

[13] Danaher \& Rossiter, (2011).Comparing perceptions of marketing communication channels, European Journal of Marketing, 45(1/2), 6-42.

[14]Duncan, Tom, (2005).IMC:Using Advertising and Promotion to Build Brands, $2^{\text {nd }}$ ed, New York, NY: McGraw Hill/Irwin.

[15] Gillin, P.( 2009). Secrets of social media marketing: how to use online conversations and customer communities to turbo-charge your business. Fresno, CA: Quill Driver Books

[16] Harvard Business School. (2006). Marketer's toolkit: The 10 strategies you need to succeed. Boston, Mass.: Harvard Business School Press

[17] Kumar, R. (2005). Sampling in research methodology: a step-by-step guide for beginners. 2nd ed. London: Sage.

[18] Lagrosen, S. (2005).Effects of the internet on the marketing communication of service. The Journal of Services Marketing, 19(2), 63-69.

[19] Saunders, M., Lewis, P. \& Thornhill, A (2007).Research methods for business students. $5^{\text {th }}$ ed. Essex: Pearson Education Limited.

[20] Shimp, T. A. (2010).Advertising promotion and other aspects of integrated marketing communications. 8th ed.Mason:South-Western Cengage Learning.

[21] Schimp, T. A. \& Andrew, J. C. (2013).Advertising promotion and other aspects of integrated marketing communications. $9^{\text {th }}$ ed. Mason:South-Western Cengage Learning, pp. 10-19.

[22] Schultz, D. E. \& Kitchen, P. J. (2009).Communication globally: An integrated marketing approach. New York: McGraw Hill Professional. 